\title{
Dapagliflozin effects on hospitalization for heart failure reduction, and major
}

\section{adverse cardiovascular events}

Abdullah Hammad Al-Temani' ${ }^{1}$, Eman Mohsen AbutalebQisi², Izzaddinn Elawad Ahmed ${ }^{3}$, Yassin

Ibrahim Mohammed ${ }^{1}$, Majed S. Alqahtani², Mustafa Hassan Elfarrag², Mustafa Albadari Mustafa ${ }^{2}$,

Osama Salih Mohammed², Salem Owaid Albalawi², and Hyder Osman Mirghani ${ }^{3}$

1. Department of Family and Community Medicine, Faculty of Medicine, University of Tabuk, Kingdom of Saudi Arabia

2. King Fahd Specialist Hospital, Ministry of Health, Tabuk, Kingdom of Saudi Arabia

3. Department of Internal Medicine, Faculty of Medicine, University of Tabuk, Saudi Arabia

\section{REVIEW}

Please cite this paper as: Al-Temani AH, Abutaleb Qisi EM, Ahmed IE, Mohammed $\mathrm{YI}$, Alqahtani MS, Elfarrag $\mathrm{MH}$, Mustafa MA, Mohammed OS, AlbalawiSO, Mirghani HO. Dapagliflozin effects on hospitalization for heart failure reduction, and major adverse cardiovascular events. AMJ 2020;13(1):16-25.

https://doi.org/10.35841/1836-1935.13.1.16-25

\section{Corresponding Author:}

Hyder Osman Mirghani

Department of Internal Medicine, Faculty of Medicine, University of Tabuk, PO Box 3378 Tabuk 51941, Saudi Arabia Email: s.hyder63@hotmail.com

\section{ABSTRACT}

\section{Background}

Until recently, there are no available preventive measures for macrovascular complications of diabetes mellitus (DM). Sodium-glucose co-transporter inhibitors (SGLT-2i) are a relatively new class of medications with cardio-renal protection. However, it is unknown, whether this is a class effect. Also, the exact mechanisms of action are not fully understood.

\section{Aims}

The current review aimed to assess dapagliflozin effects on the major cardiovascular adverse events (MACE) and heart failure hospitalization rate (HHF) and its mechanisms of action.

\section{Methods}

The Pub Med, MEDLINE, and Google Scholar databases were systematically searched for relevant articles. Articles published in the English language from the first available article up to November 2019 were approached. The terms dapagliflozin, SGLT-2i, MACE, HHF, and mechanisms of action were used with proteans AND or OR. Out of two hundred-ten articles retrieved, only twenty-nine fulfilled the inclusion and exclusion criteria.

\section{Results}

Dapagliflozin reduced HHF, all-cause mortality, bumetanide induced hyperuricemia, and interstitial fluid volume with a lower rate of diuretic use. Possible mechanisms of action were: a reduction of oxidative stress, lowering of cardiac hexosamine biosynthetic pathway activation, reduced cytosolic sodium and calcium, and increased serum magnesium. Dapagliflozin effects on MACE are mixed. The above effects seem to be a class character across various population including normal people without diabetes with no differences across gender.

\section{Conclusion}

Dapagliflozin reduced HHF (superior to empagliflozin) and all-cause mortality. The drug acts at cellular levels and not simple diuresis and haemoconcentration.

\section{Key Words}

Dapagliflozin, heart failure hospitalization, major cardiovascular adverse effects, mechanisms of action

\section{What this review adds:}

\section{What is known about this subject?}

Dapagliflozin reduces HHF, while its effects on MACE and mechanisms of action are matters of controversy. 


\section{What new information is offered in this review?}

Dapagliflozin acts on cardiac muscles and fibroblasts, induces vasodilatation in both the heart and arteries. The drug improved both systolic and diastolic dysfunction and prevent cardiac concentric remodelling. Dapagliflozin effects on electrolytes, $\mathrm{pH}$, intracellular pathways, and oxidative seem to be a class effect. Furthermore, the drug exerts favourable effects on hyperuricemia (a common morbid disease among patients with diabetes mellitus) and reduced diuretic use. Dapagliflozin is superior to empagliflozin in terms of HHF.

3. What are the implications for research, policy, or practice?

Dapagliflozin can be used safely among patients with both systolic and diastolic HF even among patients with prediabetes or normal sugar profile in particular for patients with bumetanide due to its favourable effects on hyperuricemia. Dapagliflozin is superior to empagliflozin (the first SGLT-2i to show CV benefits especially mortality) for $\mathrm{HHF}$ reduction.

\section{Introduction}

Diabetes mellitus (DM) is a public health burden (worldwide 8 per cent are affected and nearly a third are suffering from the disease in the Kingdom of Saudi Arabia).DM coexistence with hypertension, dyslipidaemia, and a high body mass index (overweight/obesity) is well-established in the context of the metabolic syndrome. The metabolic syndrome components are major risk factors for mortality, cardiovascular disease (CVD), and end-stage renal disease. ${ }^{1,2}$ SGLT-2i are Novel class of medications with cardio-renal protection, they are recommended as a second-line treatment with metformin for DM in patients at increased cardiovascular (CV) risk, chronic kidney disease or heart failure (HF). ${ }^{1}$

$\mathrm{HF}$ and DM independently contribute to significant CV mortality and morbidity. DM is the most common comorbidity among patients with $\mathrm{HF}$, and present in up to 45 per cent of patients. Atherosclerotic CVD outcomes are thought to be the major cause of morbidity and mortality among patients with diabetes. However, HF death and hospitalization have been recognized as being just as common. HF and DM are morbid costly disorders with high hospital use and mortality. ${ }^{3-5}$

Type 2 diabetes mellitus (T2DM) is a major risk factor for several CV conditions, including HF. However, until recently, no therapy to treat patients with diabetes could also reduce CV risks related to HF. HF affects approximately 2 per cent of the population worldwide, remaining a major cause of hospitalization and mortality despite innovative therapeutic approaches introduced in the past few decades. SGLT- $2 i$ including dapagliflozin seem to represent a shift in healthcare due to their favourable effects on $\mathrm{HF}$ and mortality. The final goal in the management of patients with T2DM is a reduction in CV complications and total mortality. Despite the strong evidence that SGLT-2 inhibitors are effective in $\mathrm{HF}$ reduction among patients with atrisk/established CVD and represents a paradigm shift in the management of patients with T2DM and atherosclerotic CV disease or CV risk factors, ${ }^{6}$ a striking discordance exists between evidence-based-guideline-recommended SGLT-2 inhibitors use and actual uptake in clinical practice. Paradoxically, patients with HF, hypertension, CVD, and chronic kidney disease were less likely to receive an SGLT2 inhibitor compared to their counterparts. Plausible explanations could be that doctors may be reluctant to prescribe SGLT-2i if they don't have experience using them to treat frail patients who have many comorbidities. Although it is very important to be cautious with our frail patients. However, it is unwanted to deprive them of clinically preferred treatment. In spite of being recommended for patients with CV and renal disease, SGLT$2 \mathrm{i}$ are currently under prescribed, and when they are prescribed they're being prescribed to the patients who are not likely to benefit the most. ${ }^{7,8}$ The current review aimed to assess the mechanisms of action of dapagliflozin and its effects on HHF and MACE.

\section{Methodology}

Eligibility criteria according to population intervention comparison outcome study design (PICOS):

Randomized controlled trials (RCTs), experimental, and observational studies investigating the mechanisms of action and effects of dapagliflozin on HHF and MACE were included (case reports and series were excluded).

Type of participants: Studies among adults with or without T2DM and prediabetes and experimental studies were eligible. Studies conducted on type 1 DM were not included.

Outcomes measures: HHF, nonfatal myocardial infarction, non-fatal stroke, CV death, mortality, and mechanisms of action of dapagliflozin.

Information source and search methods: A systematic electronic search was conducted in Pub Med including Epub and ahead of print, MEDLINE, Scopus, ScienceDirect and Google Scholar for relevant articles. Articles published in the English language from the first published up to November 
2019 were approached. The terms dapagliflozin, SGLT-2i, MACE, HHF, myocardial infarction, non-fatal stroke, CV death, all-cause mortality, and mechanisms of action were used in different combinations.

Studies selection and data extraction: The retrieved articles were manually searched for relevant articles, two authors (H.M. I.A.) screened the titles and abstracts to exclude irrelevant articles and any discrepancy was resolved by consensus. Out of two hundred-ten articles retrieved, only twenty-nine fulfilled the inclusion and exclusion criteria. The author's name, county, year of publication, type of study, number of patients included, the duration of follow-up if applicable, and the results were reported. The different stages of the review process were shown in the PRISMA chart $^{9}$ Figure 1.

\section{Results}

There were two hundred and ten articles, one hundred thirty-eight manuscripts remain after the removal of duplication and irrelevant articles, and only twenty-nine articles fulfilled the inclusion and exclusion criteria. There were ten randomized controlled trials, nine retrospective studies, five experimental studies, two analyses of pooled data, a prospective cohort, a post hoc analysis, and a reallife cohort study. Fourteen studies were from Europe, eight were published in the USA, six articles from Asia, and one from Australia, 803642 participants were included. The retrieved RCTs included 56709 patients, 40 per cent were from Europe, while 30 per cent were published in the USA and Asia each, the duration of the studies ranged from 2219 weeks with a mean of $81.64 \pm 97.15$ weeks. Tables 1 and 2 depicted dapagliflozin effects and mechanism of action. Dapagliflozin reduced HHF (improved both systolic and diastolic dysfunctions and reduced remodelling) and allcause mortality, bumetanide induced hyperuricemia, interstitial fluid volume, and the rate of diuretic use were also lowered. Possible mechanisms were a reduction of oxidative stress, lowering of cardiac hexosamine biosynthetic pathway activation, reduced cytosolic sodium and calcium, increased serum magnesium and mitochondrial calcium, and induced vasodilatation in the heart. This novel drug by targeting sodium-proton antiporter on cells leading to the restoration of $\mathrm{pH}$ within cells. Dapagliflozin effects on BNP and MACE are mixed. The above effects seem to be class effect across various population including normal people without diabetes with no difference between women and men. However, dapagliflozin was more effective in terms of reduction of hospitalization for heart failure compared to empagliflozin.

\section{Discussion}

In the current review, a medical claims, hospital cases/records, and medical registries-based study ${ }^{10}$ showed that SGLT-2i was associated with a lower risk of HHF and death that may be a class effects, a pooled data from five RCTs ${ }^{11}$ concluded similar findings regarding HF among users of dapagliflozin, a retrospective study ${ }^{12}$ observes a lower death among patients who received dapagliflozin. Regarding the mechanism of action, it is thought that dapagliflozin down-regulates MMP 2 expression in the HCFs, ${ }^{13}$ other benefits of dapagliflozin is the reduction of bumetanideinduced hyperuricemia as shown by a RCT. ${ }^{14}$ In the current review, a mouse model ${ }^{15}$ showed that SGLT-2i including dapagliflozin induce vasodilatation in healthy heart and reduce $\mathrm{Na}+$, while a mathematical model ${ }^{16}$ concluded that dapagliflozin reduce interstitial fluid volume to a greater extent than blood volume, thus, SGLT2 inhibitors might provide better control of congestion without reducing arterial filling and perfusion. A multi-national real-life study $^{17}$ included 40958 and showed that dapagliflozin reduced $\mathrm{HHF}$, lower risks of $\mathrm{CV}$ events and all-cause mortality compared with DPP-4 inhibitors in a real-world clinical setting and a broad T2D population. Another mechanism of action of dapagliflozin is the activation and improving cardiac function and left ventricular diastolic dysfunction and reduction of hexosamine biosynthetic pathway. ${ }^{18,19}$ The current data showed conflicting evidence regarding the MACE. However, reduction of mortality and HHF were observed ${ }^{20,21}$ the lower HHF was supported by Dawwas and colleagues, ${ }^{22}$ and Idzerda et al. ${ }^{23}$ The largest randomized controlled trial on dapagliflozin (DECLARE-TIMI 58, included 17160 patients with either established atherosclerotic CVD or multiple risk factors) showed that Dapagliflozin robustly reduced MACE and CV death/HHF among patients with myocardial infarction. Furthermore, the drug reduced $\mathrm{HHF}$ in patients with and without reduced ejection fraction (HFrEF<45 per cent). In addition, the drug reduced $\mathrm{CV}$ death and all-cause mortality in patients with HFrEF. ${ }^{24-26}$ A Markov model study of 20 years concluded the cost-effectiveness of dapagliflozin as a second-line after metformin, ${ }^{27}$ a relatively small RCT (49 patients followed for six months) showed that dapagliflozin is superior to vildagliptin regarding extraglycaemic effects. ${ }^{28} \mathrm{~A}$ real-world study showed that dapagliflozin was safe with regard to CV outcomes and resulted in lower event rates of $\mathrm{HHF}$ and $\mathrm{CV}$ mortality, ${ }^{29}$ while Weeda et al. ${ }^{30}$ observed that new loop diuretic use was less frequent among SGLT2I users; however, patterns of loop diuretic use did not differ between cohorts in those on loop diuretics at baseline. Further mechanisms of actions were increased dieresis, osmolar clearance, and serum magnesium, while sodium 
clearance and GFR were not affected. However, Eickhoff and colleagues ${ }^{32}$ concluded that Dapagliflozin exerts both osmotic and natriuretic diuretic effects in patients with type 2 diabetes and kidney damage. In the present review, Pasternak et al. $^{33}$ conducted a retrospective study in Sweden and showed that SGLT-2 use was associated with reduced risk of $\mathrm{HF}$ and any cause death, but not with MACE, further studies ${ }^{34}$ concluded the reduction of HHF among patients taking dapagliflozin. An interesting result was shown by Nassif and colleagues ${ }^{35}$ who published an RCT in the USA and showed that $\geq 5$-point improvement in Kansas City Cardiomyopathy Questionnaire overall summary score. Radholm et al. ${ }^{36}$ showed no difference between men and women regarding the risk ratio and safety outcomes, Zhang et al. $^{37}$ in their study on animal model found that dapagliflozin reverses LV concentric remodelling in HFpEF pigs partly by restraining sympathetic tone in the aorta, while Bonora et al. ${ }^{38}$ conducted a RCT and concluded no change in cardiac function using impedance cardiography.

\section{Conclusion}

Dapagliflozin reduced HHF and all-cause mortality, oxidative stress, bumetanide induced hyperuricemia, and interstitial fluid volume to a greater extent than blood volume allowing for better control of congestion without reducing arterial filling and perfusion, and a lower rate of diuretic use. Also, the drug lowered cardiac hexosamine biosynthetic pathway activation. Thus, improving cardiac function and cardiomyopathy, besides, dapagliflozin improved diastolic dysfunction, reversed concentric cardiac remodelling, reduced cytosolic sodium, and calcium, increased serum magnesium and mitochondrial calcium. This novel drug by targeting sodium-proton antiporter on cells leading to the restoration of $\mathrm{pH}$ within cells (beneficial effects including $\mathrm{HHF}$ ) or inability to rapidly recover $\mathrm{pH}$ (unwanted side effects including ketoacidosis). No effects on MPP expression were observed. Dapagliflozin effects on BNP and MACE are mixed. The above effects seem to be a class effect across various population including normal people without diabetes with no difference between women and men. However, dapagliflozin was more effective in terms of reduction of HHF.

\section{References}

1. American Diabetes Association. Diabetes Care. 2019;42:S139-S147. https://doi.org/10.2337/dc19-S012

2. Loutradis C, Papadopoulou E, Angeloudi E, et al. The beneficial actions of SGLT-2 inhibitors beyond management of hyperglycemia. Curr Med Chem. 2019. doi: 10.2174/0929867326666191029111713.

3. Cheng JWM, Colucci VJ, Kalus JS, et al. Managing diabetes and preventing heart disease: Have we found a safe and effective agent?. Ann Pharmacother. 2019;53(5):510-522. doi: 10.1177/1060028018816466. Epub 2018 Dec 5.

4. Custodio JS Jr, Duraes AR, Abreu M, et al. SGLT2 inhibition and heart failure-current concepts. Heart Fail Rev. 2018;23(3):409-418. doi: 10.1007/s10741-0189703-2.

5. Lim S, Eckel RH, Koh KK. Clinical implications of current cardiovascular outcome trials with sodium glucose cotransporter-2 (SGLT2) inhibitors. Atherosclerosis. 2018;272:33-40.

doi: 10.1016/j.atherosclerosis.2018.03.013.

6. Sharma A, Ezekowitz JA. Role of Sodium-Glucose Cotransporter-2 Inhibition in the Treatment of Adults With Heart Failure. Can J Diabetes. 2019. pii: S14992671(19)30616-1. doi: 10.1016/j.jcjd.2019.08.012.

7. McCoy RG, Dykhoff HJ, Sangaralingham L, et al. Adoption of new glucose-lowering medications in the U.S.-the case of SGLT2 inhibitors: Nationwide cohort study. Diabetes Technol Ther. 2019. doi: 10.1089/dia.2019.0213.

8. Bujang MA, Adnan TH, MohdHatta NKB, et al. A revised version of diabetes quality of life instrument maintaining domains for satisfaction, impact, and worry. J Diabetes Res. 2018;2018:5804687. doi: 10.1155/2018/5804687.

9. Knobloch K, Yoon U, Vogt PM. Preferred reporting items for systematic reviews and meta-analyses. (PRISMA) statement and publication bias. J Craniomaxillofac Surg. 2011;39(2):91-2. doi:10.1016/j.jcms.2010.11.001. PMID: 21145753.

10. Kosiborod M, Cavender MA, Fu AZ, et al. Lower risk of heart failure and death in patients initiated on sodiumglucose cotransporter-2 inhibitors versus other glucoselowering drugs: The CVD-REAL study (Comparative Effectiveness of Cardiovascular Outcomes in New Users of Sodium-Glucose Cotransporter-2 Inhibitors). Circulation. 2017;136(3):249-259. doi: 10.1161/CIRCULATIONAHA.117.029190.

11. Kosiborod M, Gause-Nilsson I, Xu J, et al. Efficacy and safety of dapagliflozin in patients with type 2 diabetes and concomitant heart failure. J Diabetes Complications. 2017;31(7):1215-1221.

doi: 10.1016/j.jdiacomp.2017.02.001.

12. Toulis KA, Willis BH, Marshall T, et al. All-cause mortality in patients with diabetes under treatment with Dapagliflozin: A population-based, open-cohort study in the health improvement network database. J Clin Endocrinol Metab. 2017;102(5):1719-1725. doi: 10.1210/jc.2016-3446.

13. Meng L, Uzui H, Guo $H$, et al. Role of SGLT1 in high 
glucose level-induced MMP-2 expression in human cardiac fibroblasts. Mol Med Rep. 2018;17(5):68876892. doi: 10.3892/mmr.2018.8688.

14. Wilcox CS, Shen W, Boulton DW, et al. Interaction Between the Sodium-Glucose-Linked Transporter 2 Inhibitor Dapagliflozin and the Loop Diuretic Bumetanide in Normal Human Subjects. J Am Heart Assoc. 2018;7(4). pii: e007046. doi: 10.1161/JAH.

15. Uthman L, Baartscheer A, Bleijlevens B, et al. Class effects of SGLT2 inhibitors in mouse cardiomyocytes and hearts: inhibition of $\mathrm{Na}+/ \mathrm{H}+$ exchanger, lowering of cytosolic $\mathrm{Na}+$ and vasodilation. Diabetologia. 2018;61(3):722-726. doi: 10.1007/s00125-017-4509-7.

16. Hallow KM, Helmlinger G, Greasley PJ, et al. Why do SGLT2 inhibitors reduce heart failure hospitalization? A differential volume regulation hypothesis. Diabetes Obes Metab. 2018;20(3):479-487. doi: 10.1111/dom.13126.

17. Persson F, Nyström T, Jørgensen ME, et al. Dapagliflozin is associated with lower risk of cardiovascular events and all-cause mortality in people with type 2 diabetes (CVD-REAL Nordic) when compared with dipeptidyl peptidase-4 inhibitor therapy: A multinational observational study. Diabetes Obes Metab. 2018;20(2):344-351. doi: 10.1111/dom.13077.

18. Soga F, Tanaka H, Tatsumi K, et al. Impact of dapagliflozin on left ventricular diastolic function of patients with type 2 diabetic mellitus with chronic heart failure. Cardiovasc Diabetol. 2018;17(1):132. doi: 10.1186/s12933-018-0775-z.

19. Lugat A, Joubert $M$, Cariou B, et al. At the heart of diabetic cardiomyopathy: Bscl2 knockout mice to investigate glucotoxicity. Med Sci (Paris). 2018;34(67):563-570. doi: 10.1051/medsci/20183406016.

20. Kosiborod M, Lam CSP, Kohsaka S, et al. CVD-REAL Investigators and Study Group. Cardiovascular Events Associated With SGLT-2 Inhibitors Versus Other GlucoseLowering Drugs: The CVD-REAL 2 Study. J Am CollCardiol. 2018;71(23):2628-2639.

doi: 10.1016/j.jacc.2018.03.009.

21. Wiviott SD, Raz I, Bonaca MP, et al. DECLARE-TIMI 58 Investigators. Collaborators (982). Dapagliflozin and Cardiovascular Outcomes in Type 2 Diabetes. N Engl J Med. 2019;380(4):347-357. doi: 10.1056/NEJMoa1812389.

22. Dawwas GK, Smith SM, Park H. Cardiovascular outcomes of sodium glucose cotransporter-2 inhibitors in patients with type 2 diabetes. Diabetes Obes Metab. 2019;21(1):28-36. doi: 10.1111/dom.13477.

23. Idzerda NMA, Stefansson BV, Pena MJ, et al. Prediction of the effect of dapagliflozin on kidney and heart failure outcomes based on short-term changes in multiple risk markers. Nephrol Dial Transplant. 2019. pii: gfz064. doi: 10.1093/ndt/gfz064.

24. McMurray JJV, DeMets DL, Inzucchi SE, et al. A trial to evaluate the effect of the sodium-glucose co-transporter 2 inhibitor dapagliflozin on morbidity and mortality in patients with heart failure and reduced left ventricular ejection fraction (DAPA-HF). Eur J Heart Fail. 2019;21(5):665-675. doi: 10.1002/ejhf.1432.

25. Furtado RHM, Bonaca MP, Raz I, et al. Dapagliflozin and cardiovascular outcomes in patients with type 2 diabetes mellitus and previous myocardial infarction. Circulation. 2019;139(22):2516-2527.

doi: 10.1161/CIRCULATIONAHA.119.039996.

26. Kato ET, Silverman MG, Mosenzon O, et al. Effect of Dapagliflozin on heart failure and mortality in type 2 diabetes mellitus. Circulation. 2019;139(22):2528-2536. doi: 10.1161/CIRCULATIONAHA.119.040130.

27. Chin KL, Ofori-Asenso R, Si S, et al. Cost-effectiveness of first-line versus delayed use of combination dapagliflozin and metformin in patients with type 2 diabetes. Sci Rep. 2019;9(1):3256. doi: 10.1038/s41598-019-40191-8.

28. Phrommintikul A, Wongcharoen W, Kumfu S, et al. Effects of dapagliflozin vsvildagliptin on cardiometabolic parameters in diabetic patients with coronary artery disease: a randomised study. $\mathrm{Br} J$ Clin Pharmacol. 2019;85(6):1337-1347. doi: 10.1111/bcp.13903.

29. Norhammar A, Bodegård J, Nyström T, et al. Dapagliflozin and cardiovascular mortality and disease outcomes in a population with type 2 diabetes similar to that of the DECLARE-TIMI 58 trial: A nationwide observational study. Diabetes Obes Metab. 2019;21(5):1136-1145. doi: 10.1111/dom.13627.

30. Weeda ER, Cassarly C, Brinton DL, et al. Loop diuretic use among patients with heart failure and type 2 diabetes treated with sodium glucose cotransporter-2 inhibitors. J Diabetes Complications. 2019;33(8):567-571. doi: 10.1016/j.jdiacomp.2019.05.001.

31. Solini A, Seghieri M, Giannini L, et al. The Effects of Dapagliflozin on Systemic and Renal Vascular Function Display an Epigenetic Signature. J Clin Endocrinol Metab. 2019;104(10):4253-4263. doi: 10.1210/jc.2019-00706.

32. Eickhoff MK, Dekkers CCJ, Kramers BJ, et al. Effects of Dapagliflozin on Volume Status When Added to ReninAngiotensin System Inhibitors. J Clin Med. 2019;8(6). pii: E779. doi: 10.3390/jcm8060779.

33. Pasternak B, Ueda P, Eliasson B, et al. Use of sodium glucose cotransporter 2 inhibitors and risk of major cardiovascular events and heart failure: Scandinavian register based cohort study. BMJ. 2019;366:14772. doi: $10.1136 /$ bmj. 14772 .

34. Shao SC, Chang KC, Hung MJ, et al. Comparative risk 
evaluation for cardiovascular events associated with dapagliflozin vs. empagliflozin in real-world type 2 diabetes patients: a multi-institutional cohort study. Cardiovasc Diabetol. 2019;18(1):120. doi: 10.1186/s12933-019-0919-9.

35. Nassif ME, Windsor SL, Tang F, et al. Dapagliflozin effects on biomarkers, symptoms, and functional status in patients with heart failure with reduced ejection fraction: The DEFINE-HF trial. Circulation. 2019;140(18):1463-1476. doi: 10.1161/CIRCULATIONAHA.119.042929. Epub 2019 Sep 16.

36. Rådholm K, Zhou Z, Clemens K, et al. Effects of sodiumglucose co-transporter- 2 inhibitors in type 2 diabetes in women versus men. Diabetes Obes Metab. 2019. doi: 10.1111/dom.13876. [Epub ahead of print]

37. Zhang N, Feng B, Ma X, et al. Dapagliflozin improves left ventricular remodeling and aorta sympathetic tone in a pig model of heart failure with preserved ejection fraction. Cardiovasc Diabetol. 2019;18(1):107. doi: 10.1186/s12933-019-0914-1

38. Bonora BM, Vigili de Kreutzenberg S, Avogaro A, et al. Effects of the SGLT2 inhibitor dapagliflozin on cardiac function evaluated by impedance cardiography in patients with type 2 diabetes. Secondary analysis of a randomized placebo-controlled trial. Cardiovasc Diabetol. 2019;18(1):106. doi: 10.1186/s12933-0190910-5.

\section{ACKNOWLEDGEMENTS}

We would like to acknowledge the Saudi National Library for accessing the databases.

\section{PEER REVIEW}

Not commissioned. Externally peer reviewed.

\section{CONFLICTS OF INTEREST}

The authors declare that they have no competing interests.

\section{FUNDING}

The research is self-funded and not supported financially by any institute or organization.

\section{ETHICS COMMITTEE APPROVAL}

N/A 
Figure 1: Flow diagram through the different phases of the systematic review (PRISMA flowchart)
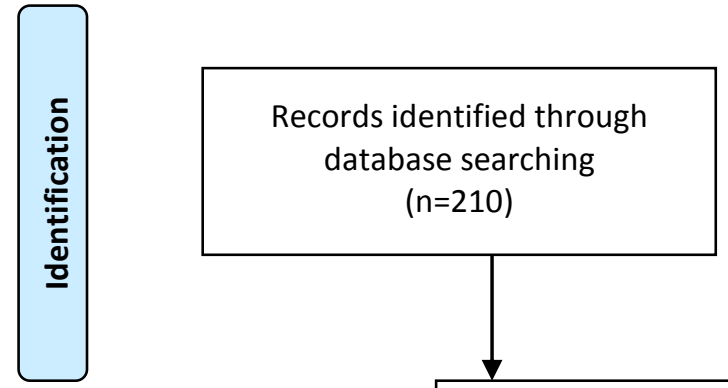

Additional records identified through other sources $n=210)$ $(n=0)$; no other sources

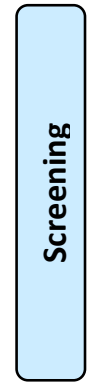

Records after duplicates removed $(n=138)$
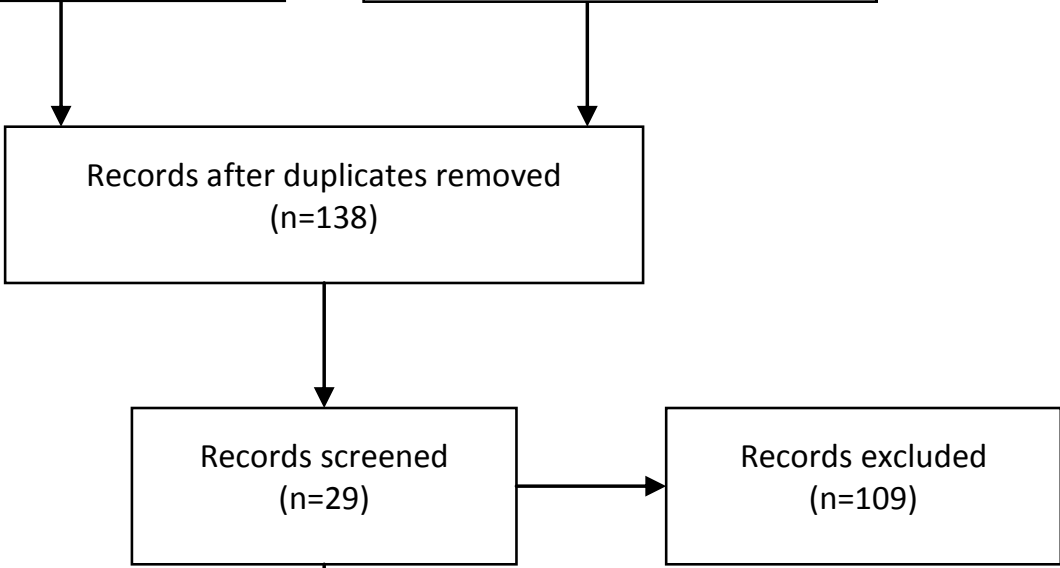

Full-text articles assessed for eligibility $(n=29)$

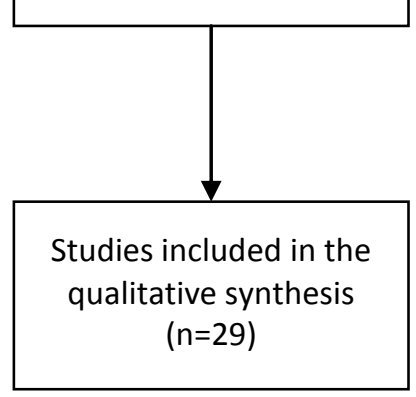

Full-text articles excluded $(n=0)$ because they are not randomized trials 
Table 1: Dapagliflozin effects on heart failure and major adverse cardiovascular events (observational and experimental studies)

\begin{tabular}{|c|c|c|c|c|c|}
\hline Author & Year & Country & No of patients & Duration & Results \\
\hline $\begin{array}{l}\text { Kosiborod et } \\
\text { al. }\end{array}$ & 2017 & USA & $\begin{array}{l}\text { Retrospective }(4,63,584 \\
\text { patients) }\end{array}$ & & $\begin{array}{l}\text { SGLT-2i was associated with a lower risk } \\
\text { of HHF and death that may be a class } \\
\text { effects }\end{array}$ \\
\hline $\begin{array}{l}\text { Kosiborod et } \\
\text { al. }\end{array}$ & 2017 & USA & $\begin{array}{l}\text { Pooled data from five } \\
\text { RCTs }\end{array}$ & & $\begin{array}{l}\text { Dapagliflozin reduced } \mathrm{HbA}_{1 \mathrm{c}} \text {, weight, } \\
\text { and SBP in patients with T2DM and } \mathrm{HF} \text {, } \\
\text { and was well tolerated. }\end{array}$ \\
\hline Toulis et al. & 2017 & UK & $\begin{array}{l}\text { Retrospective }(22,124 \\
\text { patients) }\end{array}$ & & $\begin{array}{l}\text { Lower death observed among patients } \\
\text { received dapagliflozin }\end{array}$ \\
\hline Meng et al. & 2018 & Japan & Experimental study & & $\begin{array}{l}\text { SGLT1, but not dapagliflozin (SGLT-2 } \\
\text { mainly) inhibition (through MPP } \\
\text { regulation in HCF) may be a novel } \\
\text { strategy for the treatment of DCM. }\end{array}$ \\
\hline $\begin{array}{l}\text { Uthman et } \\
\text { al. }\end{array}$ & 2018 & Netherlands & Mouse model & & $\begin{array}{l}\text { SGLT-2i induce vasodilatation in a } \\
\text { healthy heart and reduce } \mathrm{Na}^{+}\end{array}$ \\
\hline Hallow et al. & 2018 & Georgia & Mathematical model & & $\begin{array}{l}\text { By reducing I interstitial fluid volume to } \\
\text { a greater extent than blood volume, } \\
\text { SGLT2 inhibitors might provide better } \\
\text { control of congestion without reducing } \\
\text { arterial filling and perfusion }\end{array}$ \\
\hline $\begin{array}{l}\text { Persson et } \\
\text { al. }\end{array}$ & 2018 & $\begin{array}{l}\text { Sweden, } \\
\text { Denmark, } \\
\text { Norway, UK }\end{array}$ & Real-world 40,958 & & $\begin{array}{l}\text { Dapagliflozin reduced hospitalization for } \\
\text { heart failure, lower risks of CV events } \\
\text { and all-cause mortality compared with } \\
\text { DPP-4 inhibitors in a real-world clinical } \\
\text { setting and a broad T2D population }\end{array}$ \\
\hline Lugat et al. & 2018 & France & Mouse-model & & $\begin{array}{l}\text { Dapagliflozin improved cardiomyopathy } \\
\text { by hexosamine biosynthetic pathway } \\
\text { reduction }\end{array}$ \\
\hline $\begin{array}{l}\text { Kosiborod et } \\
\text { al. }\end{array}$ & 2018 & USA & $\begin{array}{l}\text { Retrospective } \\
\text { study }(2,35,064 \text { patients })\end{array}$ & & $\begin{array}{l}\text { SGLT-2i were associated with a lower } \\
\text { risk of CV events across a broad range of } \\
\text { outcomes and patient characteristics } \\
\text { (with and without cardiovascular } \\
\text { disease). }\end{array}$ \\
\hline $\begin{array}{l}\text { Dawwas et } \\
\text { al. }\end{array}$ & 2019 & USA & A retrospective study & & $\begin{array}{l}\text { Lower hospitalization compared to } \\
\text { other antidiabetic, and a lower } \\
\text { amputation risk compared to } \\
\text { sulphonylureas }\end{array}$ \\
\hline $\begin{array}{l}\text { Idzerda et } \\
\text { al. }\end{array}$ & 2019 & Netherlands & $\begin{array}{l}\text { Pooled data from seven } \\
\text { RCTs, } 482 \text { patients } \\
\text { included }\end{array}$ & & $\begin{array}{l}\text { Dapagliflozin reduced heart and kidney } \\
\text { failure events among patients with } \\
\text { diabetic kidney disease }\end{array}$ \\
\hline Chin et al. & 2019 & Australia & Markov model & $\begin{array}{l}20 \text { years } \\
\text { model } \\
\text { period }\end{array}$ & $\begin{array}{l}\text { Compared to first-line metformin } \\
\text { monotherapy followed by the gradual } \\
\text { addition of dapagliflozin, first-line use of } \\
\text { combination dapagliflozin and } \\
\text { metformin is likely to be a cost-effective }\end{array}$ \\
\hline $\begin{array}{l}\text { Norhammar } \\
\text { et al. }\end{array}$ & 2019 & Sweden & $\begin{array}{l}\text { Observational study. } \\
28408 \text { participants }\end{array}$ & & $\begin{array}{l}\text { Dapagliflozin was safe about CV } \\
\text { outcomes and resulted in lower event } \\
\text { rates of HHF and CV mortality in real- } \\
\text { world }\end{array}$ \\
\hline Weeda et al. & 2019 & USA & $\begin{array}{l}\text { Prospective cohort } \\
\text { including } 1,500 \text { heart } \\
\text { failure patients }\end{array}$ & $\begin{array}{l}12 \\
\text { months }\end{array}$ & $\begin{array}{l}\text { New loop diuretic use was less frequent } \\
\text { among SGLT2I users; however, patterns } \\
\text { of loop diuretic use did not differ } \\
\text { between cohorts in those on loop } \\
\text { diuretics at baseline. }\end{array}$ \\
\hline Eickhoff et & 2019 & Denmark & Post-hoc analysis of two & 12 weeks & Dapagliflozin exerts both osmotic and \\
\hline
\end{tabular}




\begin{tabular}{|l|l|l|l|l|l|}
\hline al. & & & $\begin{array}{l}\text { RCTs=69 with } \\
\text { albuminuria }\end{array}$ & $\begin{array}{l}\text { natriuretic diuretic effects in patients } \\
\text { with type 2 diabetes and kidney damage }\end{array}$ \\
\hline $\begin{array}{l}\text { Pasternak et } \\
\text { al. }\end{array}$ & 2018 & Sweden & $\begin{array}{l}\text { Retrospective, 20,983 } \\
\text { patients }\end{array}$ & $\begin{array}{l}42 \\
\text { months }\end{array}$ & $\begin{array}{l}\text { SGLT-2 use was associated with reduced } \\
\text { risk of heart failure and any cause of } \\
\text { death, but not with major cardiovascular } \\
\text { events }\end{array}$ \\
\hline Shao et al, & 2019 & Taiwan & $\begin{array}{l}\text { Comparative study, } \\
\text { 12,681patients on } \\
\text { dapagliflozin vs. } \\
\text { empagliflozin }\end{array}$ & $\begin{array}{l}\text { Lower risk of heart failure observed with } \\
\text { dapagliflozin compared to empagliflozin }\end{array}$ \\
\hline $\begin{array}{l}\text { Rådholm et } \\
\text { al. }\end{array}$ & 2019 & Sweden & An analysis of 4 RCTs & $\begin{array}{l}\text { No difference between men and women } \\
\text { regarding the risk ratio and safety } \\
\text { outcomes }\end{array}$ \\
\hline Zhang et al. & 2019 & China & An animal study on pigs & 9 weeks & $\begin{array}{l}\text { Dapagliflozin reverses LV concentric } \\
\text { remodelling in HFpEF pigs partly by } \\
\text { restraining sympathetic tone in the } \\
\text { aorta }\end{array}$ \\
\hline
\end{tabular}

Table 2: Dapagliflozin effects on HHF and MACE (randomized controlled trials)

\begin{tabular}{|c|c|c|c|c|c|}
\hline Author & Year & Country & Methods & Follow-up & Results \\
\hline Wilcox et al. & 2018 & USA & $\begin{array}{l}\text { Forty-two healthy participants } \\
\text { on fixed diet of } 110 \mathrm{mmol} / \mathrm{day} \\
\mathrm{Na}^{+} \text {were randomized to } \\
\text { dapagliflozin } 10 \mathrm{mg} / \text { day and } \\
\text { bumetanide } 1 \mathrm{mg} / \mathrm{day} \text { or both } \\
\text { for one week }\end{array}$ & 7 days & $\begin{array}{l}\text { The first dose combination was not } \\
\text { additive regarding } \mathrm{Na}^{+} \text {excretion. } \\
\text { However, synergistic effects were } \\
\text { observed after one week. Also, } \\
\text { dapaglilozin reversed bumetanide- } \\
\text { induced hyperuricemia }\end{array}$ \\
\hline Soga et al. & 2018 & Japan & $\begin{array}{l}\text { Patients on antidiabetic } \\
\text { medications and stable HF were } \\
\text { prescribed dapagliflozin } \\
5 \mathrm{mg} / \text { day and followed for } \\
\text { changes in mitral inflow E and } \\
\text { mitral e' annular velocities, as } \\
\text { primary end points, and left } \\
\text { ventricle, atrial volumes, and } \\
\text { brain natriuretic peptide (BNP) } \\
\text { as secondary end points. }\end{array}$ & 6 months & $\begin{array}{l}\text { Dapagliflozin } 5 \mathrm{mg} \text { improved left } \\
\text { ventricular diastolic dysfunction, } \\
\text { no significant effects on BNP was } \\
\text { observed }\end{array}$ \\
\hline Wiviott et al. & 2019 & England & $\begin{array}{l}17,160 \text { patients with/at risk of } \\
\text { CVD assigned to dapagliflozin or } \\
\text { placebo, the primary outcomes } \\
\text { were MACE, HHF, CV death, the } \\
\text { secondary end points were } \\
\text { reduction in GFR, new end } \\
\text { stage renal disease, and death } \\
\text { from CV or renal disease, and } \\
\text { all cause mortality. }\end{array}$ & 4.2 years & $\begin{array}{l}\text { MACE not affected by } \\
\text { dapagliflozin, while HHF and CV } \\
\text { death were reduced }\end{array}$ \\
\hline Furtado et al. & 2019 & USA & $\begin{array}{l}\text { 17,160 patients with either } \\
\text { established atherosclerotic CVD } \\
\text { or multiple risk factors were } \\
\text { assigned to either dapagliflozin } \\
\text { or placebo, The primary end } \\
\text { points were composite of MACE } \\
\text { CV death, MI, or ischemic } \\
\text { stroke) and the composite } \\
\text { of CV death or HHF. }\end{array}$ & 4.2 years & $\begin{array}{l}\text { Dapagliflozin robustly reduced } \\
\text { MACE and cardiovascular } \\
\text { death/hospitalization for heart } \\
\text { failure among patients with/at risk } \\
\text { of CVD }\end{array}$ \\
\hline Kato et al. & 2019 & Japan & $\begin{array}{l}\text { DECLARE-TIMI } 58 \text { trial } 17,160 \\
\text { patients with HF, ejection } \\
\text { fraction (EF) was collected, the }\end{array}$ & 4.2 years & $\begin{array}{l}\text { Dapagliflozin reduced HHF in } \\
\text { patients with and without HFrEF } \\
\text { and reduced cardiovascular death }\end{array}$ \\
\hline
\end{tabular}




\begin{tabular}{|c|c|c|c|c|c|}
\hline & & & $\begin{array}{l}\text { patients were categorized and } \\
\text { reduced }(<45 \%) \text { or normal EF. }\end{array}$ & & $\begin{array}{l}\text { and all-cause mortality in patients } \\
\text { with HFrEF. }\end{array}$ \\
\hline $\begin{array}{l}\text { Phrommintikul } \\
\text { et al. }\end{array}$ & 2019 & Thailand & $\begin{array}{l}\text { Forty-nine T2D patients with } \\
\text { coronary artery disease were } \\
\text { randomly assigned } \\
\text { to dapagliflozin or vildagliptin }\end{array}$ & 6 months & $\begin{array}{l}\text { More favourable effects of } \\
\text { dapagliflozin compared to } \\
\text { vildagliptin regarding blood } \\
\text { pressure and weight reduction }\end{array}$ \\
\hline Solini et al. & 2019 & Italy & $\begin{array}{l}\text { Forty hypertensive patients } \\
\text { were assigned to } \\
\text { dapagliflozin } 10 \mathrm{mg} \text { or } \\
\text { hydrochlorothiazide } 12.5 \mathrm{mg}\end{array}$ & 4 weeks & $\begin{array}{l}\text { Diuresis and osmolar clearance } \\
\text { increased with dapagliflozin, and } \\
\text { serum magnesium increased, while } \\
\text { sodium clearance and GFR not } \\
\text { affected. }\end{array}$ \\
\hline McMurray et al. & 2019 & UK & $\begin{array}{l}4744 \text { patients with } \mathrm{HF}(\mathrm{EF}<40 \%) \\
\text { with and without } \mathrm{DM} \text { were } \\
\text { assigned to dapagliflozin } 10 \mathrm{mg} \\
\text { or placebo }\end{array}$ & $\begin{array}{l}18.2 \\
\text { months }\end{array}$ & $\begin{array}{l}\text { Dapagliflozin reduced } \\
\text { hospitalization or an urgent visit } \\
\text { resulting in intravenous therapy } \\
\text { for heart failure and CV }\end{array}$ \\
\hline Nassif et al. & 2019 & USA & $\begin{array}{l}\text { RCT including } 263 \text { participants } \\
\text { with and without DM and HF } \\
\text { with reduced EF were assigned } \\
\text { to dapagliflozin or placebo. }\end{array}$ & 12 weeks & $\begin{array}{l}\geq \text { A 5-point improvement in Kansas } \\
\text { City Cardiomyopathy } \\
\text { Questionnaire overall summary } \\
\text { score and HF was observed among } \\
\text { dapagliflozin users, no effects on } \\
\text { BNP }\end{array}$ \\
\hline Bonora et al. & 2019 & Italy & $\begin{array}{l}\text { Thirty-three patients with } \\
\text { T2DM were given dapagliflozin } \\
\text { or placebo }\end{array}$ & 12 weeks & $\begin{array}{l}\text { No change in cardiac function } \\
\text { using impedance cardiography }\end{array}$ \\
\hline
\end{tabular}

DAPA-TIMI 58: Dapagliflozin Effect on Cardiovascular Events-Thrombolysis in Myocardial Infarction 58

HHF: hospitalization for heart failure

DCM: dilated cardiomyopathy

HFr EF: heart failure with a reduced ejection fraction

CV: cardiovascular

LV: left ventricle

BNP: brainnatriureticpeptide

MMPs: matrix metalloproteinases 